\title{
Grüber's ligament as a useful landmark for the abducens nerve in the transnasal approach
}

\author{
Ryosuke Tomio, MD, ${ }^{1}$ Masahiro Toda, MD, PhD, ${ }^{1}$ Agung Budi Sutiono, MD, PhD, ${ }^{3}$ \\ Takashi Horiguchi, MD, PhD, ${ }^{1}$ Sadakazu Aiso, MD, PhD, ${ }^{2}$ and Kazunari Yoshida, MD, PhD' \\ Departments of ${ }^{1}$ Neurosurgery and ${ }^{2}$ Anatomy, School of Medicine, Keio University, Tokyo, Japan; and ${ }^{3}$ Department of \\ Neurosurgery, Padjadjaran University Faculty of Medicine, Dr. Hasan Sadikin Hospital, Bandung, Indonesia
}

\begin{abstract}
OBJECT Extended endoscopic transnasal surgeries for skull base lesions have recently been performed. Some expert surgeons have attempted to remove tumors such as chordomas, meningiomas, and pituitary adenomas in the clival region using the transnasal approach and have reported abducens nerve injury as a common complication. There have been many microsurgical anatomical studies of the abducens nerve, but none of these studies has described an anatomical landmark of the abducens nerve in the transnasal approach. In this study the authors used cadaver dissections to describe Grüber's ligament as the most reliable landmark of the abducens nerve in the transnasal transclival view.
\end{abstract}

METHODS The petroclival segment of the abducens nerve was dissected in the interdural space-which is also called Dorello's canal, the petroclival venous gulf, or the sphenopetroclival venous confluence-using the transnasal approach in 20 specimens obtained from 10 adult cadaveric heads.

RESULTS The petroclival segment of the abducens nerve clearly crossed and attached to Grüber's ligament in the interdural space, as noted in the transnasal view. The average length of the dural porus to the intersection on the abducens nerve was $5.2 \pm 1.0 \mathrm{~mm}$. The length of the posterior clinoid process (PCP) to the intersection on Grüber's ligament was $6.4 \pm 2.6 \mathrm{~mm}$. The average width of Grüber's ligament at the midsection was $1.6 \pm 0.5 \mathrm{~mm}$.

CONCLUSIONS Grüber's ligament is considered a useful landmark, and it is visible in most adults. Thus, surgeons can find the abducens nerve safely by visualizing inferolaterally along Grüber's ligament from the PCP.

http://thejns.org/doi/abs/10.3171/2014.10.JNS132437

KEY WORDS anatomy; Grüber's ligament; abducens nerve; transnasal; transsphenoidal; endoscopic

$\mathrm{E}$ XPANDED endoscopic transnasal surgeries for skull base lesions have recently become popular. Some expert surgeons performed endoscopic transclival removal of tumors such as meningiomas, chordomas, and pituitary adenomas and reported a risk of abducens nerve injuries with such surgeries. . $^{4,5,710}$

The microsurgical anatomy of the abducens nerve (cranial nerve VI) has been described many times by wellknown authors such as Dorello, Destrieux, and Laconetta. ${ }^{1,2,8}$ The relationship of the abducens nerve and Grüber's ligament in the petroclival segment, and the transnasal endoscopic microanatomical view of the abducens nerve, have also been described in previous reports. However, no one has yet described an anatomical landmark of the abducens nerve in the interdural space-also called Dorello's canal, the petroclival venous confluence, or the sphenope- troclival venous gulf-in the transnasal transclival view. ${ }^{2}$ In this study we show that Grüber's ligament is the most reliable landmark of the abducens nerve in the transnasal transclival view using cadaver dissection.

\section{Methods}

This study was performed at the Clinical Anatomy Laboratory in the School of Medicine, Keio University, with 10 adult cadaveric heads ( 20 sides of 10 heads). The heads were embalmed in formalin solution. All 20 specimens were dissected, and for 18 specimens of 9 heads photographs were taken and measurements were made. Seven heads (14 sides) were injected with colored silicone, red for arteries and blue for veins. The specimens had been dissected with the aid of visualization through operative microscopes. 


\section{Results}

\section{Abducens Nerve and Grüber's Ligament in the Interdural Space}

We first removed the intranasal and intrasphenoid sinus structures extensively to expose the clivus bone, carotid prominence, and anterior sellar wall (Fig. 1A). Two heads exhibited the presellar type of sphenoidal sinus, 4 heads presented as the sellar type, and the other 4 heads exhibited the postsellar type. ${ }^{13}$ The clivus bone was thin and easily drilled in the postsellar type, but was thick in the presellar type. After we drilled the lateral side of the clivus and the anterior and medial walls of the carotid prominence, we were able to see the periosteal dura, which lines the inside of that bone. We then cut and removed the periosteal dura carefully in the superolateral direction to the rear of the internal carotid artery (ICA) to find Grüber's ligament when visualizing it from an angle of $10^{\circ}-20^{\circ}$ (Fig. 1B). We drilled the thin posteromedial bone wall that surrounds the ICA before cutting the periosteal dura in the lateral direction. Grüber's ligament, the right abducens nerve, and the dorsal meningeal artery were exposed in the lateral region in this interdural space, which is called Dorello's canal, the petroclival venous confluence, or the sphenopetroclival venous gulf (Fig. 1C). ${ }^{2}$

Both Grüber's ligament and the abducens nerve were present in this shallow interdural space, almost behind the posterior wall bone that surrounds the ICA. Grüber's ligament ran inferolaterally from the attachment of the posterior clinoid process (PCP) to the petrous apex. We found Grüber's ligament in this interdural space near the PCP. Then the abducens nerve could be safely exposed along Grüber's ligament inferolaterally. We confirmed the intersection of the abducens nerve and Grüber's ligament in this lateral interdural space in all 10 heads. This intersection point was confirmed easily in 8 heads because it was located on the medial side behind the ICA. However, the intersection was located almost behind the ICA in 2 heads, and thus ICA sacrifice and drilling of the posterior wall bone surrounding the ICA were needed to confirm the intersection.

There were many fibrous trabeculae that were attached
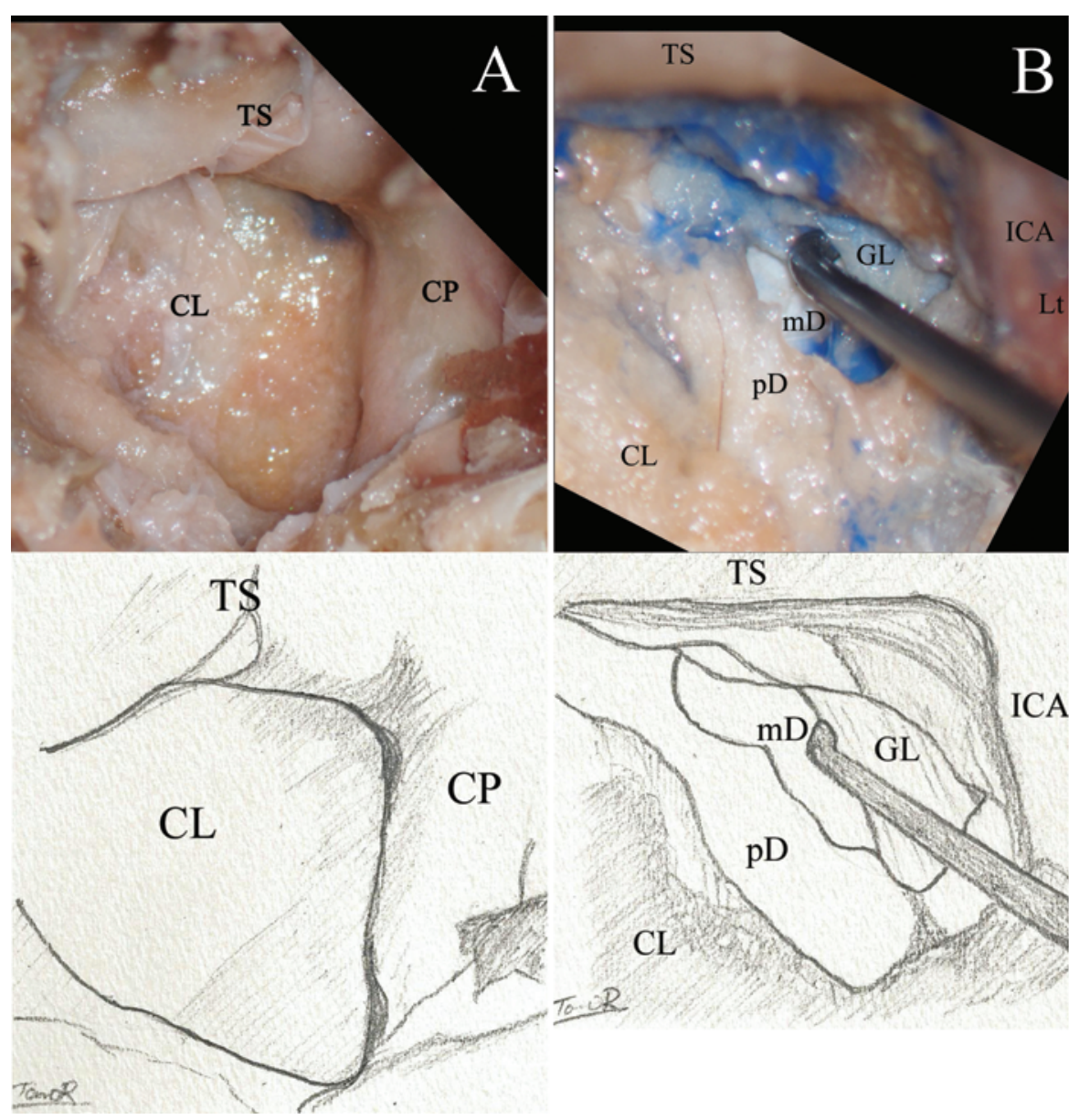

TS
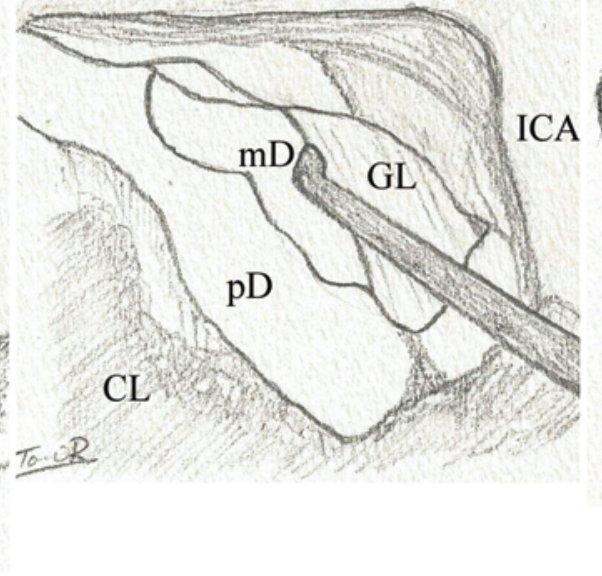

ICA

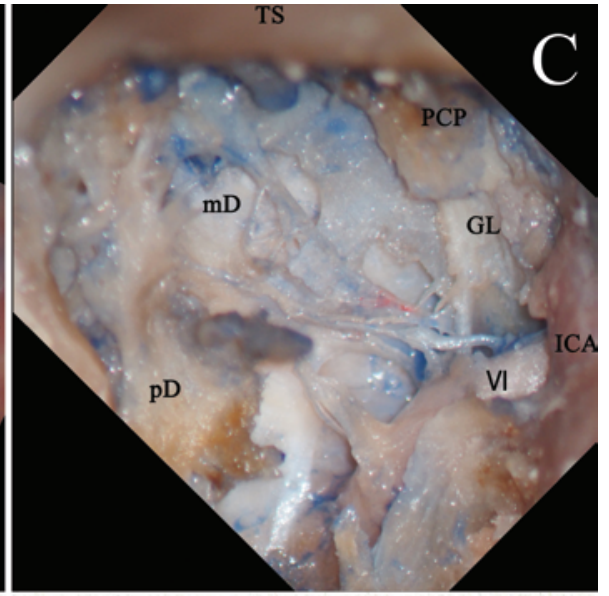

TS

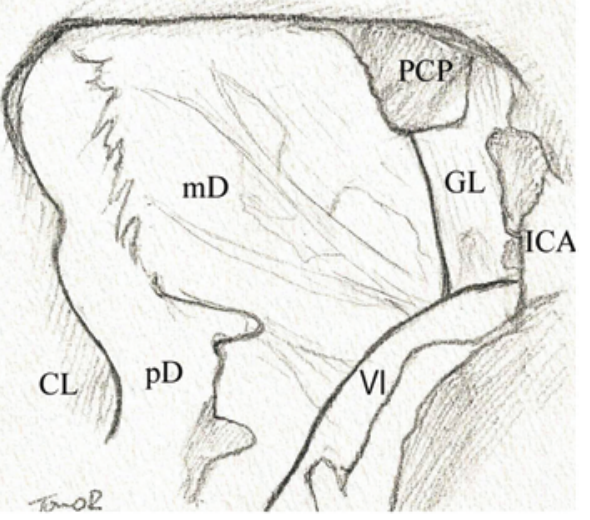

FIG. 1. Photographs and corresponding illustrations showing the transnasal dissection of the left side of a head with colored silicone injections. A: The clivus (CL), carotid prominence (CP), and tuberculum sellae (TS) were exposed after expanded removal of the intranasal structures and the anterior wall of the sphenoid sinus. B: The clivus and the anterior wall of the ICA were drilled out. The periosteal dura $(\mathrm{pD})$ was cut and opened superolaterally to find Grüber's ligament $(\mathrm{GL})$ near the PCP. This interdural space was lined with the meningeal dura $(\mathrm{mD})$. C: The abducens nerve $(\mathrm{VI})$ was exposed along Grüber's ligament inferolaterally. The intersection point of Grüber's ligament and the abducens nerve was also confirmed. Lt = left. Copyright Ryosuke Tomio. Published with permission. Figure is available in color online only. 
to Grüber's ligament and the abducens nerve. The abducens nerve and its dural sleeve were adhered to the periosteal dura behind the posterior wall bone surrounding the ICA at this intersection point in all of the specimens. Contact between the abducens nerve and Grüber's ligament was confirmed in most cases, and only 1 specimen showed a distance between them. The adhesion between the abducens nerve and Grüber's ligament was tight and strong in 2 heads and slight or nonexistent in the other heads.

After this intersection, the abducens nerve ran in the superolateral direction to the dorsal side of the petrous part of the right ICA. Using retraction of the right ICA, we confirmed that the abducens nerve ran anterior at the lateral side of the right ICA in the cavernous sinus (Fig. 2).

We clearly recognized the dural entrance porus where the abducens nerve enters the interdural space from the subdural space with the dural sleeve. This dural entrance porus was located more inferior to the intersection and just behind the medial line of the ICA or slightly medial to the ICA in most cases. We confirmed the cisternal compartment of the right abducens nerve after cutting the men- ingeal dura and the arachnoid to expose the pons in the brainstem.

We dissected 10 heads, and the same structures were confirmed on both sides in all of the heads. To avoid abducens nerve injury, the dissection should start from the superomedial part of the clivus to first recognize Grüber's ligament, and then the inferolateral part can be safely exposed along Grüber's ligament. Grüber's ligament was thus considered a useful landmark of the abducens nerve in this interdural space.

\section{Measurements of the Abducens Nerve and Grüber's Ligament}

We performed measurements of 18 specimens in 9 heads (Fig. 3). The average length of the dural porus to the intersection on the abducens nerve was $5.2 \pm 1.0 \mathrm{~mm}$ (range 3.5-7 mm) in total, $5.4 \pm 1.0 \mathrm{~mm}$ (range 3.5-7 mm) on the right side, and $4.9 \pm 0.9 \mathrm{~mm}$ (range $3.5-6 \mathrm{~mm}$ ) on the left side (Table 1). The length of the PCP to the intersection on Grüber's ligament was $6.4 \pm 2.6 \mathrm{~mm}$ (range $4-12 \mathrm{~mm}$ ) in total, $6.8 \pm 2.3 \mathrm{~mm}$ (range $5-12 \mathrm{~mm}$ ) on the right side, and $6.0 \pm 2.8 \mathrm{~mm}$ (range $4-12 \mathrm{~mm}$ ) on the left
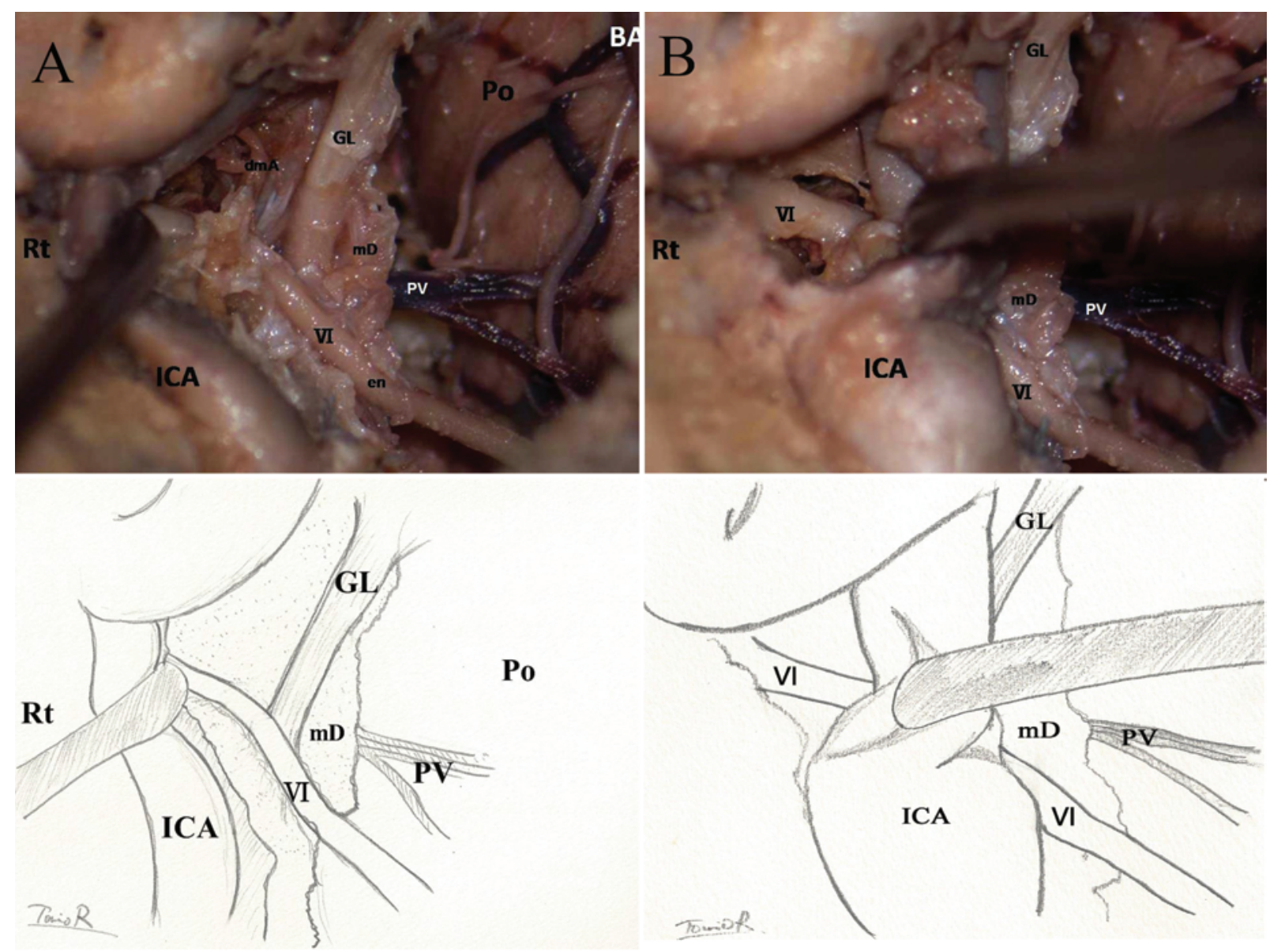

FIG. 2. Photographs and illustrations showing the right side of a cadaver head without colored silicone injections. A: The intersection point of Grüber's ligament (GL) and the abducens nerve $(\mathrm{VI})$ were clearly visualized when the ICA was retracted laterally. B: The ICA was retracted medially to show the cavernous sinus part of the abducens nerve, which runs anteriorly on the right lateral side of the ICA. $B A=$ basilar artery; $\mathrm{dmA}=$ dorsal meningeal artery; en = dural entrance porus; $\mathrm{mD}=$ meningeal dura; $P 0$ = pons; $\mathrm{PV}=$ petrosal vein; $\mathrm{Rt}=$ right; $\mathrm{VI}=$ abducens nerve. Copyright Ryosuke Tomio. Published with permission. Figure is available in color online only. 


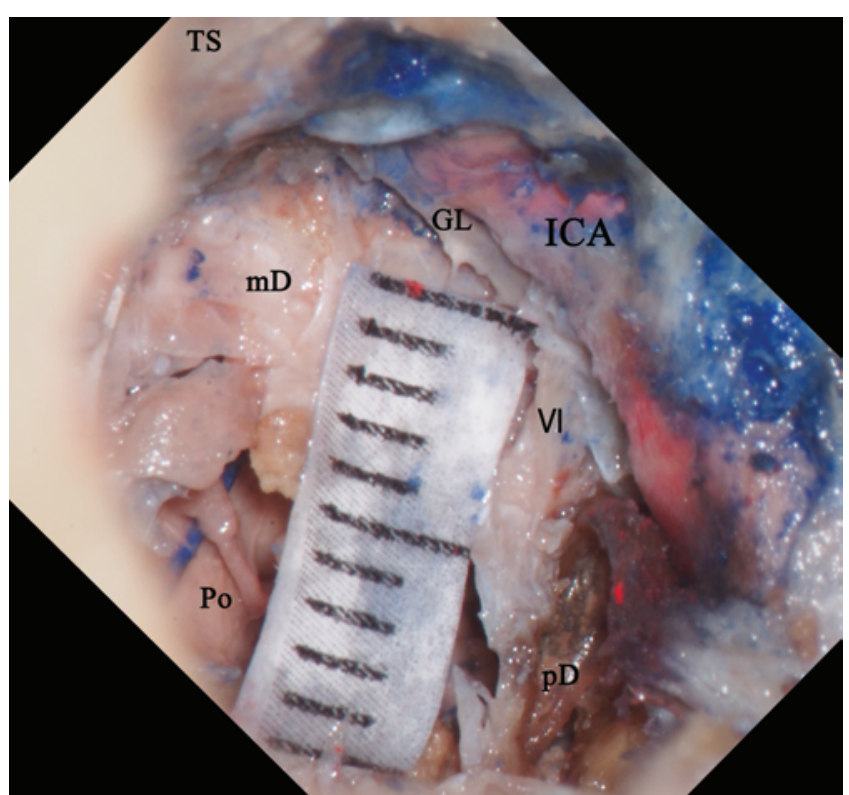

FIG. 3. Photograph displaying dissection of the left side of a cadaver head with colored silicone injections. After Grüber's ligament (GL) and the abducens nerve $(\mathrm{VI})$ were dissected in the interdural space behind the medial line of the ICA, the meningeal dura $(\mathrm{mD})$ and arachnoid were opened to confirm the pons (Po) and cisternal compartment of the abducens nerve. The measurements of the length of the dural porus to the intersection on the abducens nerve were performed with a ruler (in millimeters). $\mathrm{pD}=$ periosteal dura; $\mathrm{TS}=$ tuberculum sellae. Figure is available in color online only.

side. The average width of Grüber's ligament at the midsection was $1.6 \pm 0.5 \mathrm{~mm}$ (range $1-2 \mathrm{~mm}$ ) in total, $1.5 \pm$ $0.5 \mathrm{~mm}$ (range $1-2 \mathrm{~mm}$ ) on the right side, and $1.6 \pm 0.5$ $\mathrm{mm}$ (range 1-2 $\mathrm{mm}$ ) on the left side.

Both the average lengths of the dural porus to the intersection on the abducens nerve and the PCP to the intersection on Grüber's ligament were longer on the right side. In addition, we estimated the differences in these lengths on both sides in each head. Both of the maximum bilateral differences in the lengths of the dural porus to the intersection and of the PCP to the intersection were $3 \mathrm{~mm}$. The locations of the intersection points were apparently asymmetrical in these 2 of the 9 heads.

\section{Discussion}

We considered Grüber's ligament a useful landmark for the abducens nerve in the transnasal approach. Grüber's ligament is a well-known ligament that bridges the PCP and the upper clivus to the petrous apex. This ligament appears to be the largest fibrous trabeculation in the interdural space; it is also called the superior sphenopetrosal ligament. This ligament is butterfly shaped $78 \%$ of the time and is sometimes calcified. ${ }^{1,2,3,11}$ Icke et al. have reported that $22 \%$ of the time this ligament is triangular shaped, with the widest end attached to either the PCP or petrous apex. $^{3}$

Grüber's ligament exists as a complete structure in $52 \%$ of adults and exhibits hypoplasia and fragmentation in 38\%. ${ }^{3}$ We confirmed Grüber's ligament in all 10 heads, and apparent fragmentation was confirmed in only 1 head. In the study of Icke et al., the length of Grüber's ligament was approximately $12-13 \mathrm{~mm}$, and its width was $4-6 \mathrm{~mm}$ at the PCP and petrous apex, which was compatible with our measurements. ${ }^{3}$ Some previous reports have shown that the abducens nerve usually runs to the inferior side of Grüber's ligament, but sometimes it runs superiorly.,12 The abducens nerve ran to the inferior side of Grüber's ligament in all 10 of the cadaver heads we examined. Previous reports have also shown that the abducens nerve adheres tightly to Grüber's ligament with its dural sleeve, which consists of the meningeal dura and arachnoid in this interdural space, ${ }^{6,9}$ and its mobility is limited by Grüber's ligament. This intersection and the pressure of Grüber's ligament are often considered the reason for traumatic abducens nerve palsy. ${ }^{6}$ Contact between the abducens nerve and Grüber's ligament was also confirmed in all of our cases, but the adhesion was not tight in most cases. The adhesion between the abducens nerve and the periosteal dura was tighter.

Our cadaver dissection showed that the intersection point of the abducens nerve and Grüber's ligament was noted after the removal of the clivus bone and periosteal dura in the transnasal approach. This intersection point is in the interdural space that is called Dorello's canal, the petroclival venous confluence, or the sphenopetroclival venous gulf. In addition, this intersection is located laterally and almost behind the petrous part of the bone surrounding the ICA. The periosteal dura is in front of this intersection, and the meningeal dura is behind it in the transnasal approach. Grüber's ligament always runs superomedially to inferolaterally, and the abducens nerve runs inferomedially to superolaterally from the dural entrance porus in the transnasal view. We suggest that a

TABLE 1. Results of measurements of the abducens nerve and Grüber's ligament

\begin{tabular}{lccc}
\hline \multicolumn{1}{c}{ Measurement $(\mathrm{mm})$} & Rt Side & Lt Side & Total \\
\hline Length of dural porus to intersection on the abducens nerve & & & \\
\hline Mean \pm SD & $5.4 \pm 1.0$ & $4.9 \pm 0.9$ & $5.2 \pm 1.0$ \\
\hline Range & $3.5-7$ & $3.5-6$ & $3.5-7$ \\
\hline Length of PCP to intersection on Grüber's ligament & & & $6.4 \pm 2.6$ \\
\hline Mean \pm SD & $6.8 \pm 2.3$ & $6.0 \pm 2.8$ & $4-12$ \\
\hline Range & $5-12$ & $4-12$ & $1.6 \pm 0.5$ \\
\hline Width of Grüber's ligament at midsection & & & $1-2$ \\
\hline Mean \pm SD & $1.5 \pm 0.5$ & $1.6 \pm 0.5$ & $1-2$ \\
\hline Range & $1-2$ & & 12 \\
\hline
\end{tabular}


safe way to approach the abducens nerve in the transnasal approach is to first find Grüber's ligament in the superomedial part near the PCP in the interdural space, then to remove the clivus bone and periosteal dura inferolaterally along Grüber's ligament, and finally to reach the intersection point of Grüber's ligament and the abducens nerve.

Although this interdural space is a venous sinus in normal anatomy, some tumors in the clival region can invade and fill this space. Meningiomas, chordomas, and pituitary adenomas are sometimes found in this region. Normal structures such as vessels appear to be easily displaced by these tumors. However, both Grüber's ligament and the abducens nerve are fixed tightly by many structures, and their relationship does not appear to be changed by the tumors. Thus, we suggest that Grüber's ligament would be a useful landmark for the abducens nerve in tumor removal surgeries that use the transnasal approach.

The expanded endoscopic transnasal approach is a current method to remove clival region tumors. Anatomical knowledge of Grüber's ligament in the transnasal view and its relationship with the abducens nerve is helpful for avoiding abducens nerve injury in transnasal surgery.

\section{Conclusions}

Grüber's ligament is considered a useful landmark and is visible in most adults. Thus, surgeons can find the abducens nerve safely by visualizing inferolaterally along Grüber's ligament from the PCP.

\section{Acknowledgments}

We thank Dr. Nobuaki Imanishi and Dr. Tadakazu Aiso (Department of Anatomy, School of Medicine Keio University) for their contributions to the Clinical Anatomy Laboratory.

\section{References}

1. Destrieux C, Velut S, Kakou MK, Lefrancq T, Arbeille B, Santini JJ: A new concept in Dorello's canal microanatomy: the petroclival venous confluence. J Neurosurg 87:67-72, 1997

2. Iaconetta G, Fusco M, Samii M: The sphenopetroclival venous gulf: a microanatomical study. J Neurosurg 99:366375,2003

3. Icke C, Ozer E, Arda N: Microanatomical characteristics of the petrosphenoidal ligament of Gruber. Turk Neurosurg 20:323-327, 2010

4. Kassam A, Snyderman CH, Mintz A, Gardner P, Carrau RL: Expanded endonasal approach: the rostrocaudal axis. Part II.
Posterior clinoids to the foramen magnum. Neurosurg Focus 19(1):E4, 2005

5. Kassam AB, Gardner P, Snyderman C, Mintz A, Carrau R: Expanded endonasal approach: fully endoscopic, completely transnasal approach to the middle third of the clivus, petrous bone, middle cranial fossa, and infratemporal fossa. Neurosurg Focus 19(1):E6, 2005

6. Katsuno M, Yokota H, Yamamoto Y, Teramoto A: Bilateral traumatic abducens nerve palsy associated with skull base fracture-case report. Neurol Med Chir (Tokyo) 47:307309,2007

7. Koutourousiou M, Gardner PA, Tormenti MJ, Henry SL, Stefko ST, Kassam AB, et al: Endoscopic endonasal approach for resection of cranial base chordomas: outcomes and learning curve. Neurosurgery 71:614-625, 2012

8. Lang J: Skull Base and Related Structures: Atlas of Clinical Anatomy. Stuttgart: Schattauer Verlag, 1995, pp 85-86

9. Ozveren MF, Erol FS, Alkan A, Kocak A, Onal C, Türe U: Microanatomical architecture of Dorello's canal and its clinical implications. Neurosurgery 60 (2 Suppl 1):ONS1ONS8, 2007

10. Snyderman CH, Pant H, Carrau RL, Prevedello D, Gardner P, Kassam AB: What are the limits of endoscopic sinus surgery?: the expanded endonasal approach to the skull base. Keio J Med 58:152-160, 2009

11. Tubbs RS, Sharma A, Loukas M, Cohen-Gadol AA: Ossification of the petrosphenoidal ligament: unusual variation with the potential for abducens nerve entrapment in Dorello's canal at the skull base. Surg Radiol Anat 36:303-305, 2014

12. Umansky F, Elidan J, Valarezo A: Dorello's canal: a microanatomical study. J Neurosurg 75:294-298, 1991

13. Vidić B: The postnatal development of the sphenoidal sinus and its spread into the dorsum sellae and posterior clinoid processes. Am J Roentgenol Radium Ther Nucl Med 104:177-183, 1968

\section{Author Contributions}

Conception and design: Tomio, Today, Sutiono. Acquisition of data: Tomio, Sutiono. Analysis and interpretation of data: Tomio. Drafting the article: Tomio, Toda. Critically revising the article: all authors. Reviewed submitted version of manuscript: all authors. Approved the final version of the manuscript on behalf of all authors: Tomio. Administrative/technical/material support: Tomio, Horiguchi, Aiso, Yoshida. Study supervision: Tomio, Toda, Horiguchi, Yoshida.

\section{Correspondence}

Ryosuke Tomio, Department of Neurosurgery, Keio University School of Medicine, 35 Shinanomachi, Shinjuku, Tokyo, 1608582, Japan.email: tomy0807@hotmail.com. 